\title{
Design of Solar Transmission System using Fiber Optic for Indoor Lighting
}

\author{
Elita Fidiya Nugrahani ${ }^{\text {a* }}{ }^{\text {, Reza Arraffi Birahmatika }}{ }^{a}$, Epri Wahyu Pratiwi ${ }^{a}$, \\ Sekartedjo $\mathrm{K}^{\mathrm{a}}$ \\ ${ }^{a}$ Department of Engineering Physics, Institut Teknologi Sepuluh Nopember Surabaya, Indonesia
}

\begin{abstract}
Transmission of fiber solar lighting system is a lighting system using sunlight as a source. The system consists of two main components, there are: solar collectors and optical fiber. Solar collector is used to collect and focus sunlight into the focal point. Sunlight that received by collector is transmitted by optical fiber into the room, primarily through efficiency of the collector system. In this final project, we designed the transmission systems via optical fiber for lighting on the Photonics Laboratory ITS. Transmission of solar lighting systems used parabolic collector as a major collector and end glow plastic optical fiber as the transmission with length of $50 \mathrm{~m}$. There are four types of collector systems were designed, i.e. parabolic, parabolic with flat mirrors, parabolic with pyramid and parabolic with a cone. Characterization system consists of measuring reflectance values, the output intensity of the optical fiber, and the intensity light distribution in the room. The results of measurements of the reflectance $(\mathrm{R})$ collector surface with paint gray and silver are 0.225 and 0.475 , respectively. In the measurement light output intensity of the optical fiber with variation types of collector systems, it is obtained that the highest value from the combination of parabolic collector with a cone. Distribution of light output from the optical fiber in the room was also calculated and measured.
\end{abstract}

Keywords: collector; optical fiber; solar lighting

\section{Main text}

The world's energy needs from year to year increase exponentially . It is estimated that in 2035 increased by nearly four times the energy needs in 2010 . Approximately $24 \%$ of the total energy used by buildings , and $35.8 \%$ of the energy used in buildings for lighting systems [1]. Therefore, we need a system that can reduce lighting energy consumption in buildings, particularly through the use of renewable energy, namely solar energy instead of conventional energy .

Some research to reduce energy consumption on lighting with solar energy has been done, for example by using a glass roof , and modify the window . But the lighting solution in a way that has aspects of accumulated heat from the light source of the sun and lead to an increase in the room temperature [2]. Another solution offered is to use solar lighting . Research on solar lighting using optical fibers has been started since 1982 , namely research on parabolic collectors, as the light receiver. Until now it has developed many other studies including those by Mahya in 2007 , namely the manufacture of prototype solar hybrid lighting the sunlight through fiber optics with LED lights, the prototype ribbed $50 \mathrm{~cm}$ cube . This thesis explores about how to obtain a sufficient efficiency of the transmission of solar lighting system for indoor lighting. This study is part of a hybrid solar lighting systems

\footnotetext{
* Corresponding author. Tel.: +62 85231007690

E-mail address: rabsy.arraffi@gmail.com
} 
research in photonics ITS Engineering Laboratory. The purpose of this thesis is to obtain an increase in the efficiency of the transmission system through increased employment of solar lighting collector system for photonics Mechanical Engineering Physics Laboratory ITS . The limit problem in this research is the design of the system used for indoor Engineering Laboratory photonics and fiber optics are used manifold end glow with a length of $50 \mathrm{~m}$.

\section{Theory}

\section{a. Solar lighting}

C. Kandili said solar energy transmission by optical fiber is called the transmission of concentrated solar energy via optical fibers (TCSEvOF). The system consists of a concentrator TCSEvOF light and fiber optic. Concentrators are also called light or light collector serves to receive energy from the sun and focus it with a high energy density. While the optical fiber used as a transmission medium solar energy [3]. TCSEvOF for room lighting applications used on buildings that do not receive sunlight, for example, in the basement, the building is enclosed by other buildings, and enclosed spaces. In addition to energy savings, lighting TCSEvOF system is used because the quality of light that has a spectrum that is closer to the visual response of the human eye [4].

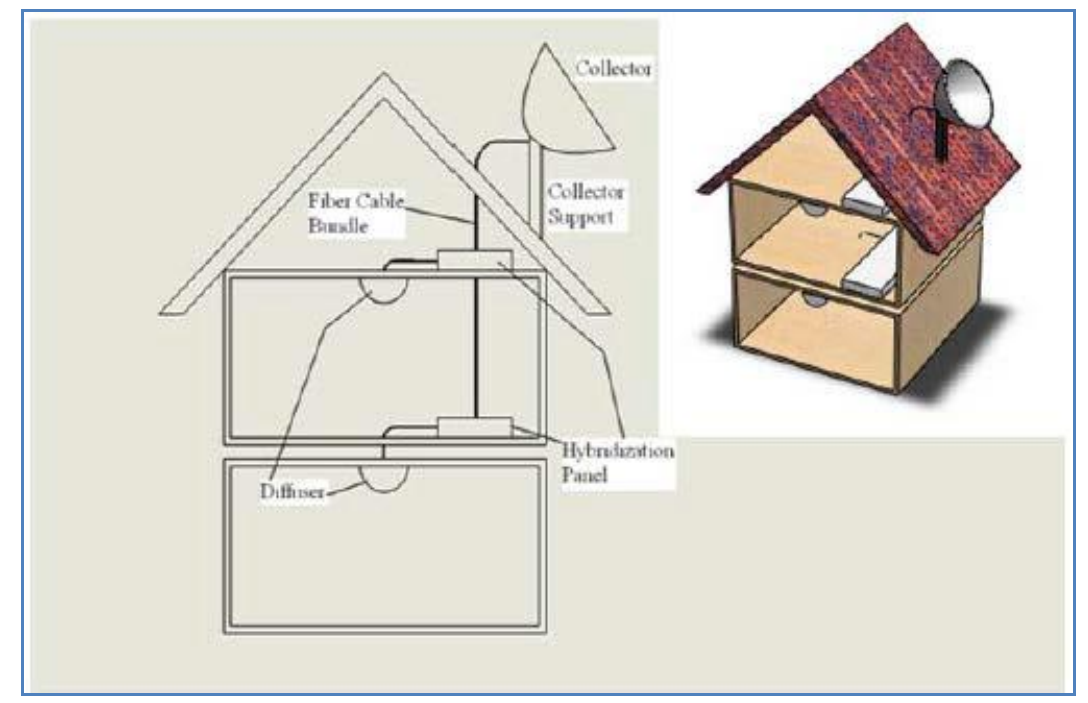

Figure 1. Schematic transmission via fiber optic solar lighting [4].

\section{b. Solar collector}

Solar collector is a device that receives and collects solar energy. Solar collectors or collectors of light applied to the water heater, solar cell, solar lighting, and so on. There are some basic forms of light collectors are flat, parabolic, and parabolic cylinder [6]. In its development, the three forms are combined. Patrick Couture journals published in IEEE examine the light collector is a parabolic shape, multi-surface, half ball, and tapered [5].

\section{- Parabolic collector}

The main collector used in this thesis is a parabolic collector. Collectors of this type have been adjusting to its use is via fiber optic solar lighting. Parabolic collector ability to focus light energy into a smaller area is needed because of the extent of acceptance of small optical fibers [6]. 
- $\quad$ Patrick couture collector in the journal

There are several types of collectors were studied by Patrick Couture in 2008. Research was based on experiments. This collector is used to obtain light and fiber optic mengfokuskannya to flat panels. There are four types of experiments are used as a parabolic collector, collector multisurface, semicircular collector, and tapered collector. Optical fiber is placed at the end of the collector. Based on the experimental results, the highest efficiency values obtained by using tapered collector [5].

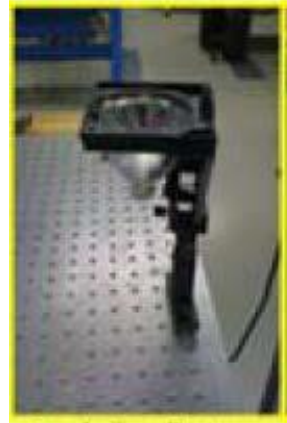

Parabolic collector

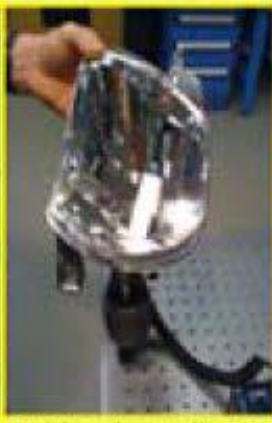

Multi-vurface collector Semircircular collector

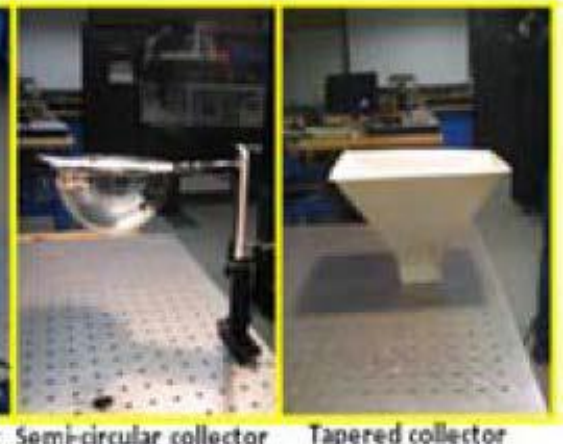

Tapered collector

Figure 2. Collector type in the journal of Patrick Couture.

\section{Material and methods}

a. Block diagram of solar lighting system

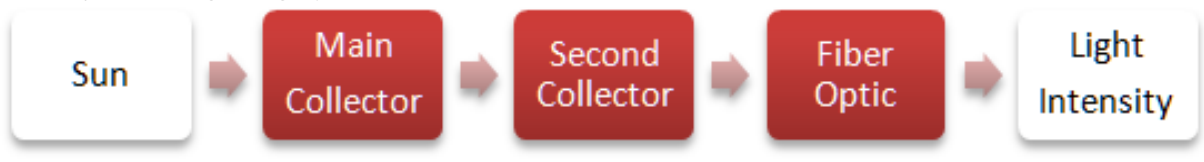

Figure 3. Collector type in the journal of Patrick Couture.

In the design of the transmission of solar lighting systems, things that affect the output intensity of the optical fiber is light intensity, the extent of the parabola, the extent of the optical fiber, loss optical fiber, and the coupling between the optical fiber and the collector. Here is the output equation that is substituted system of equations and the energy density loss optical fiber:

$I_{o}=\frac{I_{i} \cdot A_{s} \cdot R \cdot r_{f}^{2}}{\left(\frac{(f-h) \cdot d}{2 \cdot f}\right)^{2}} / 10^{\frac{l_{f}}{10}}$

Where: $\mathrm{I}_{\mathrm{o}}=$ intensity of light output from the optical fiber (lux), $\mathrm{I}_{\mathrm{i}}=$ intensity of solar light (lux), As = area of a parabolic surface $\left(\mathrm{m}^{2}\right), \mathrm{R}=$ reflectance value, $\mathrm{f}=$ focal length of the parabola parabola $(\mathrm{m}), \mathrm{h}=$ height of the tip of the optical fiber was on the basis of parabolic collector $(\mathrm{m}), \mathrm{d}=$ diameter of the parabola $(\mathrm{m}), \mathrm{r}_{\mathrm{f}}$ $=$ radius of the optical fiber $(\mathrm{m}), \mathrm{l}_{\mathrm{f}}=$ loss optical fiber $(\mathrm{dB})$

\section{b. Components}

\section{- Parabolic collector}

The main collector used is a parabola. This is due to the nature of the parabola to focus the incoming light rays parallel. Sunlight received by a satellite dish and is considered as a parallel light is focused at 
the focal point. Parabola used metal iron with a diameter of $80 \mathrm{~cm}$ and a surface area of $0.518 \mathrm{~m}^{2}$.

- Fiber optics

Optical fiber used in this study has the following specifications: Type: Solid core end glow cable core Material: Resin Polymethil methacrylate (PMMA) cladding Material: Fluorinated Polymer Material jacket: black PVC core refractive index: 1.49 Numerical aparture: 0.5 core diameter: $6 \mathrm{~mm}$ acceptance angle: $60^{\circ}$ optical fiber types have been selected because of the range of intensities that can be transmitted is looked waves, making it suitable to be used as lighting.

\section{Analysis}

a. Alternative location of the collector

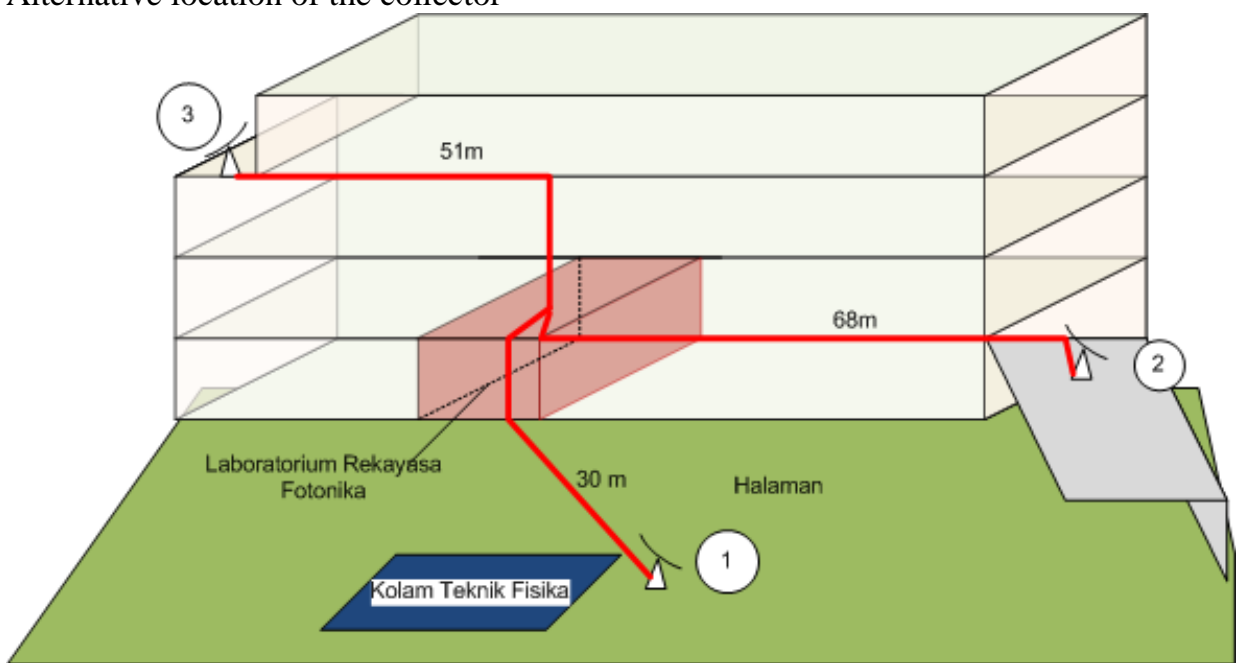

Figure 4. Alternative laying collector in Building E.

Place the laying of collector are important in the transmission of solar lighting system design because the shorter the distance, the less the loss due to the optical fiber. There are three options in the Department of Physics is used as a measurement of light intensity. Three sites have been selected based on the location is always sunlit morning till evening and Engineering Laboratory located in photonics. Three sites located on the edge of an Engineering Physics, second floor, and the fourth floor.

\begin{tabular}{|c|c|c|c|}
\hline No & Place & Distance $(\mathrm{m})$ & $\begin{array}{c}\text { Total loss optical } \\
\text { fiber }(\mathrm{dB})\end{array}$ \\
\hline 1 & In front of laboratory & 30 & 9 \\
\hline 2 & Second floor & 68 & 20,4 \\
\hline 3 & Fourth floor & 51 & 15,3 \\
\hline
\end{tabular}

The shortest distance is 30 meter, the collector is placed in front of the lab and there is loss $9 \mathrm{~dB}$ or $14 \%$ efficiency fiber optic input to output. But here used optical fiber with a length of $50 \mathrm{~m}$, so it has a total loss of $15 \mathrm{~dB}$ optical fiber, the efficiency of $3.22 \%$. Based on the review and acceptance of the intensity range, the most likely location is in front of the laboratory. 
b. Measurement of reflectance values $(\mathrm{R})$ parabolic collector

Reflectance Value (R) will affect the amount of solar energy that is reflected to the focal point of the parabola. $\mathrm{R}=0$ for a perfectly absorbing black surface and 1 for a surface that can reflect light perfectly. $\mathrm{R}$ depends on the material, surface flatness, and color. In this final painting which is varied with gray and silver.

Measurement of reflectance values using a laser pointer that has an intensity of 105 lux beginning. Reflectance values range from $0-1$, calculated from the ratio of the intensity of the reflection and intensity are fired at the beginning of the parabola.

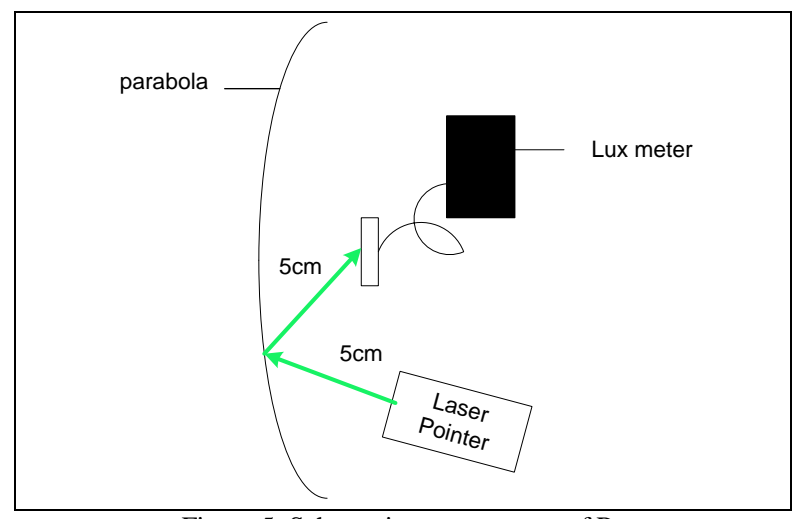

Figure 5. Schematic measurement of R.

Table 2. $\mathrm{R}$ on a collector with a variety of paint colors gray and silver.

\begin{tabular}{|c|c|c|}
\hline Colour Paint Variation & Intensity Reflection (lux) & $\mathrm{R}$ \\
\hline Grey & 23.7025 & 0.225 \\
\hline Silver & 49.9 & 0.475 \\
\hline
\end{tabular}

There are four types of solar collectors used in this study. These four designs using parabolic solar collector as a major collector. The satellite dish is made of metal with gray paint. The color of the surface of the parabola affect the reflectance value. When the conversion is done into a silver color, reflectance value increased to double the 0.225 initially be 0.475 . This research has also been conducted by Patrick who proved that silver color produces a higher power output than the $23 \%$ white, and $7 \%$ higher than the glossy white color.

c. Output optical fibers

Subsequent measurement of the intensity of optical fiber output (Io) to variations in the distance from the bottom end of the fiber optic parabolic (h). The test is performed with four different types of collector systems are: parabolic, parabolic with flat mirrors, parabolic rectangular pyramid, and a satellite dish with a cone. 
- Parabolic collector system

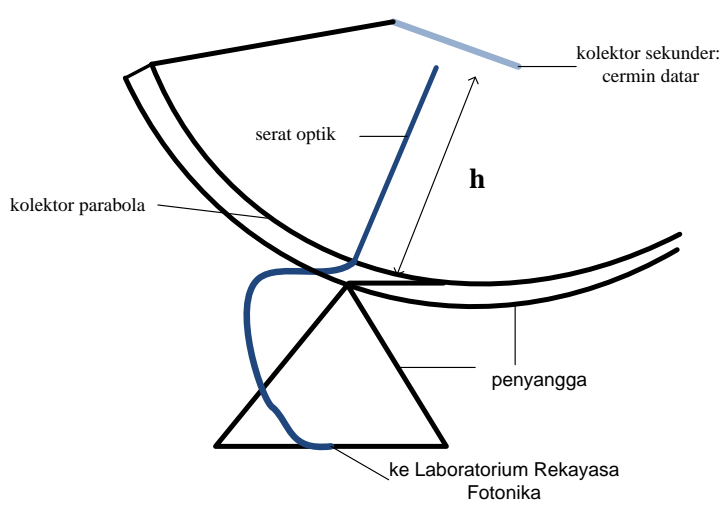

Figure 6. Scheme parabolic collector system and a flat mirror.

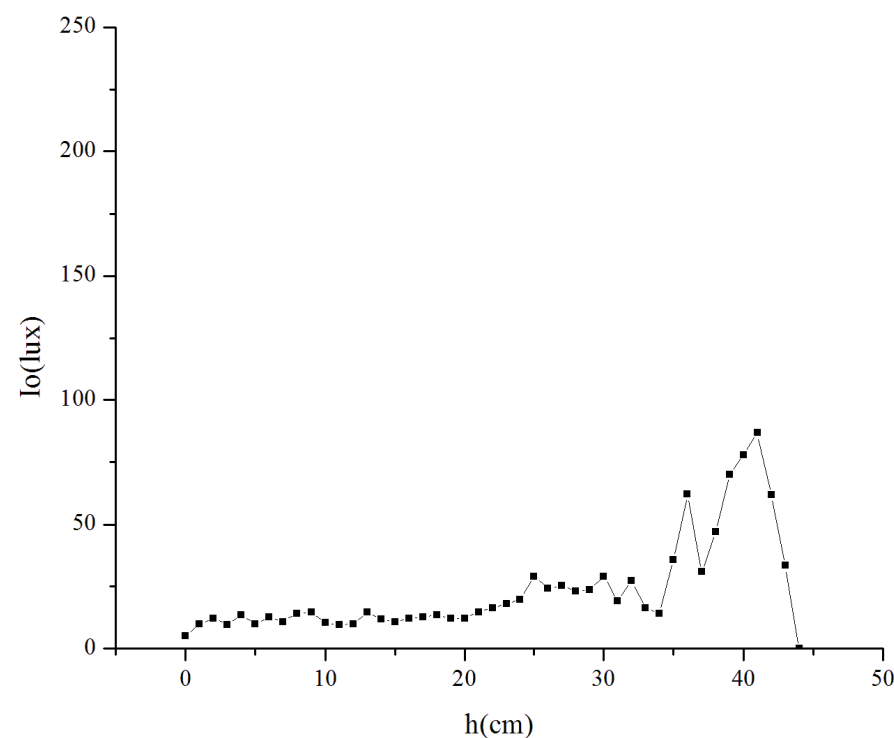

Figure 7. Graph showing the relationship $\mathrm{h}$ and Io on parabolic collector system and a flat mirror.

The initial design is a parabolic collector system with a flat mirror as a secondary collector. This type of collector is adopting the final draft Mahya [2]. Perpendicular sunlight with parabolic collector is reflected in the focus point . Beam of light towards a focal point that will be accepted by the plane mirror and reflected into the optical fiber .

The graph has a peak at $h=42$, which means that the reflection of light from mirrors greatest accepted at that point. Whereas if $\mathrm{h}$ is more than $42 \mathrm{~cm}$, Io getting smaller as the tip of the optical fiber closer to the mirror and the cause is not fully reflected light from the mirror can be caught. At 0 $30 \mathrm{~h}$ region, the intensity of the reflection of the mirror tends to show the same results Io measurement, it is because the area of the flat mirror reflection is widening. Collectors of this type can result in a maximum output of 82 lux when $h=42$. The difficulty of the use of this type of collector is the coupling between an optical fiber and a flat mirror. 
- Configuration parabolic collector system

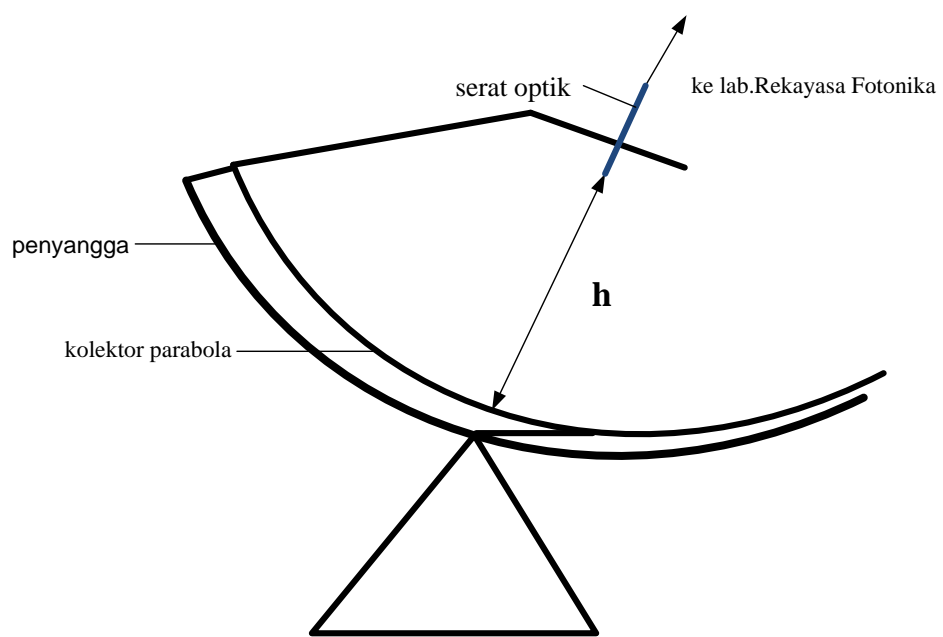

Figure 8. Scheme parabolic collector system.

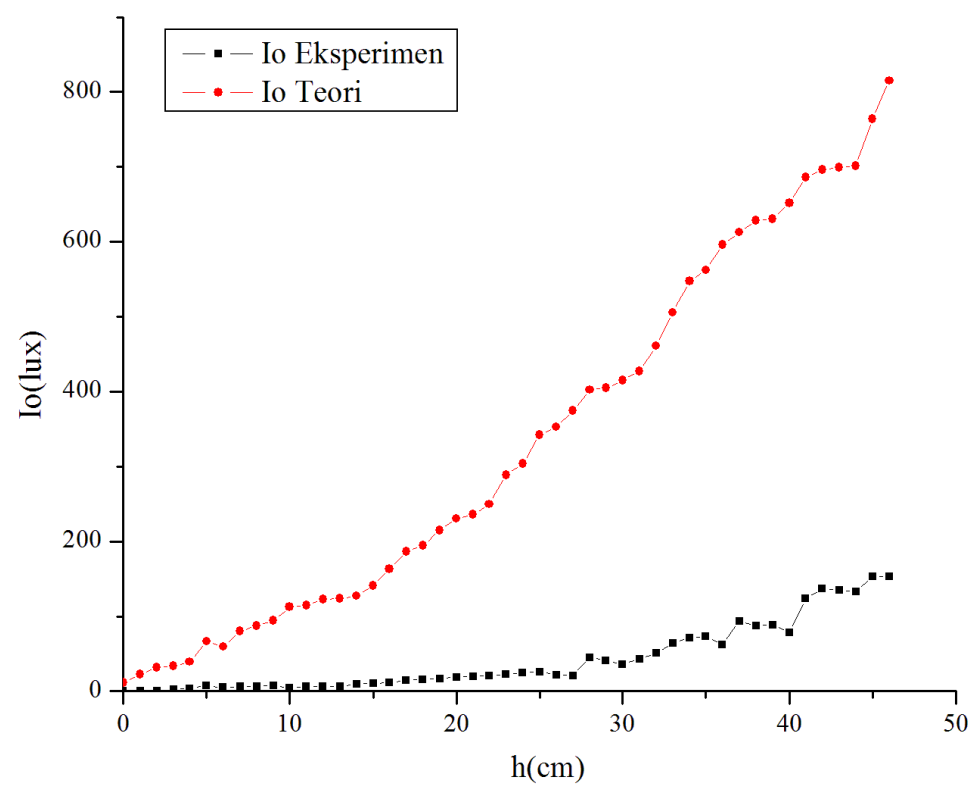

Figure 9. Graphs relationship h and Io on parabolic collector system.

The second design of a parabolic collector without secondary collector, wherein the optical fiber is placed at the focus of the parabola. This design adoption from Kandili [4] . Rays of light reflected by the parabolic collector received by the optical fiber at the focus .

Difference in differences based on experimental data and theoretical equation 1 is 9 times. The highest intensity is obtained when $\mathrm{h}=46$ is $153 \mathrm{lux}$. Experimental values have a standard deviation of 2.38 lux.Penyebab taking the measurements of differences in the value of the theory and experimental results due to the loss caused by the coupling between optical fibers and parabolic collector. Optical fiber acceptance angle of $60 \mathrm{o}$, while the sunlight from the collector parabola to the focus point of an 
angle $76^{\circ}$. Rays that come have a greater angle than the acceptance angle of optical fiber, causing light entering the optical fiber is smaller. Moreover there is a aberration of parabolic collectors that causes a focus area is not a point, so that the incoming light. New problems in the design of this type is the broadening of the focal point. So that the intensity of the reflected by the parabolic collector is not fully inserted into the optical fiber.

- Parabolic collector system configuration and rectangular pyramid

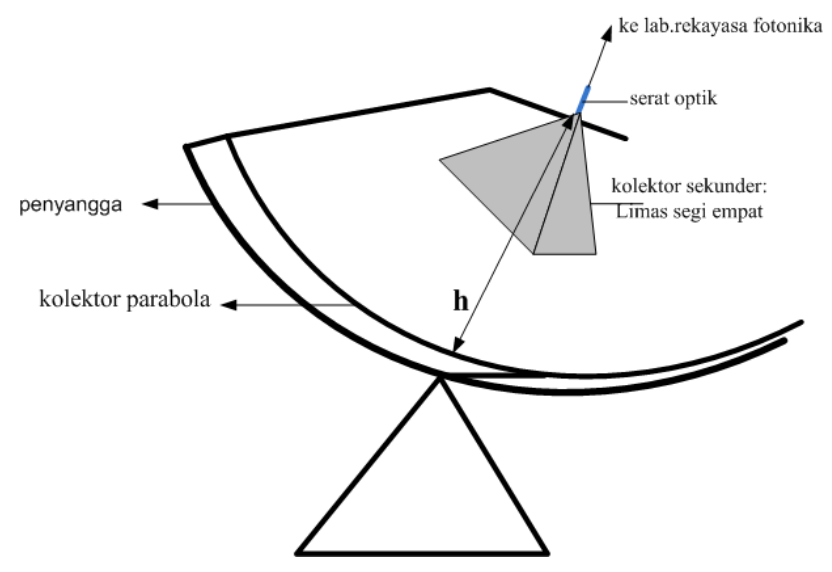

Figure 10. Schematic parabolic collector system and a rectangular pyramid.

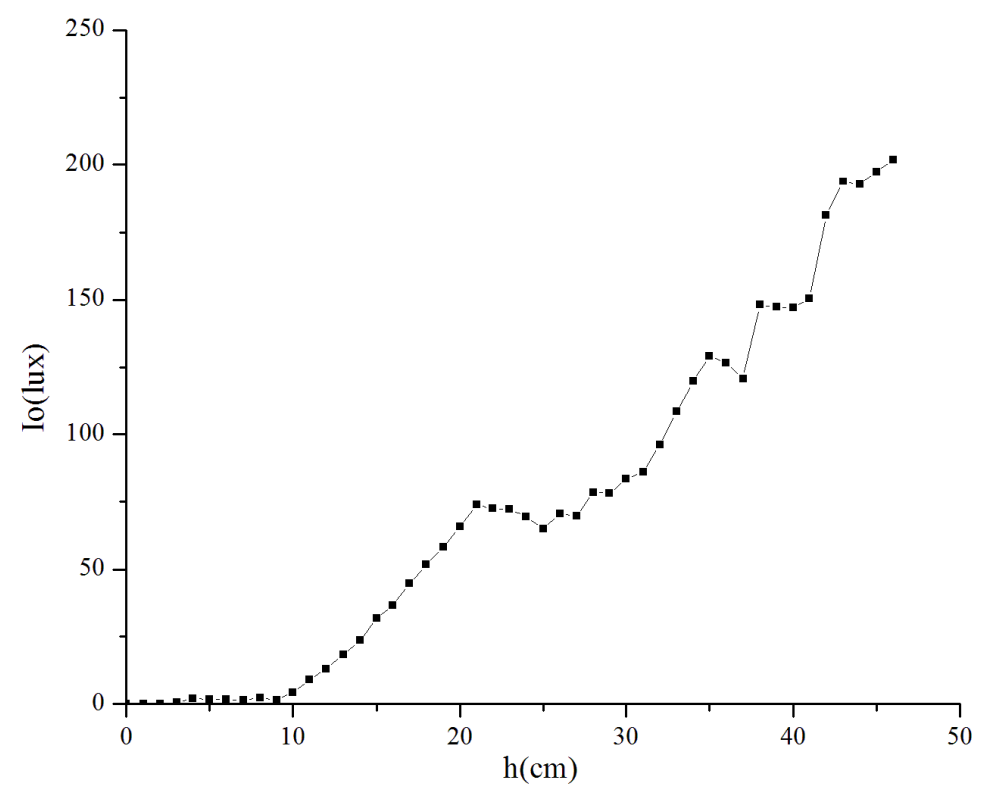

Figure 11. Graphs relationship $\mathrm{h}$ and Io on parabolic collector system and a rectangular pyramid.

The third draft by using parabolic collector system and a secondary collector rectangular pyramid coated aluminum foil is placed around the focus of the parabola. This type of collector combines a parabolic collector as a major collector and collector rectangular pyramid as a collector second . 
Collectors of this type have not been investigated previously. The research is mostly done on a parabolic collector. While some researching on the rectangular pyramid collector without a satellite dish , for example Patrick Couture . Patrick suggests bahawa main collector using quadrilateral pyramid obtain results in higher efficiency than parabolic collectors, multisurface, and semicircular . Corner of a rectangular pyramid is tailored to the acceptance angle of the optical fiber is $60^{\circ}$. The hope of all beams of light that can be captured by a quadrilateral pyramid entirely enter into the optical fiber While the height of the pyramid quadrilateral by $10 \mathrm{~cm}$.

The experimental results combined a parabolic collector and rectangular pyramid shows that the largest optical fiber output intensity is 201 lux when $\mathrm{h}=46 \mathrm{~cm}$. The collector system has a standard deviation of 4.4 lux measurements .

- Configuration parabolic collector system and cones

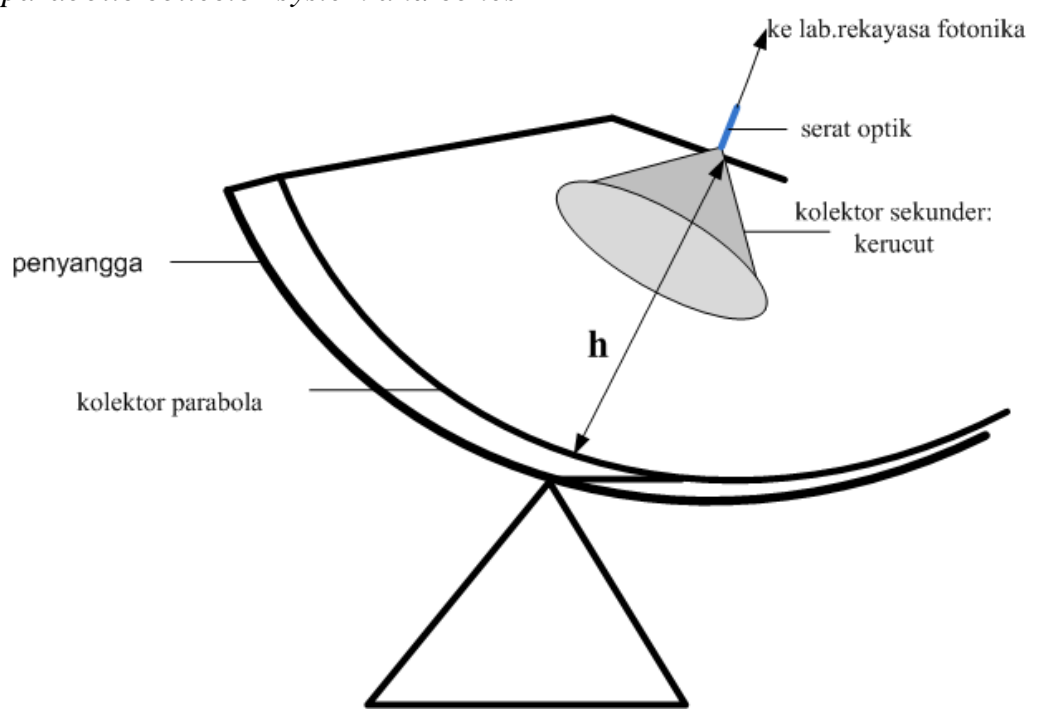

Figure 12. Schematic parabolic collector system and cones. 


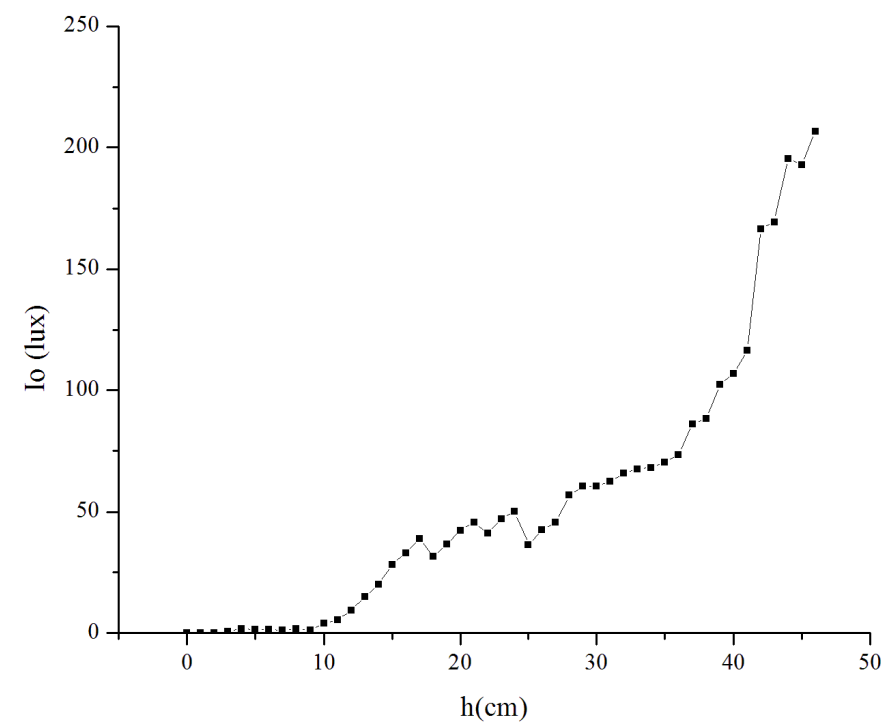

Figure 13. Graph showing the relationship $\mathrm{h}$ and Io on parabolic collector system and a rectangular pyramid.

The design of the four configurations, namely a parabolic collector system as a major collector and collector cone as secondary. Cone placement together with the placement of a rectangular pyramid . Cone is designed with an angle of $60^{\circ}$ in accordance with the acceptance angle of an optical fiber with a $10 \mathrm{~cm}$ high . Collectors with a conical type has not been studied previously. The experimental results showed the highest output intensity is obtained when $\mathrm{h}=46$ is 206 lux . The collector system has a standard deviation of 4.68 lux measurements . Based on the experimental results, using a parabolic collector collectors both in the form of a quadrilateral pyramid or cone obtain a higher yield than the use of a flat mirror or without a second collector. Collector system using a secondary collector or parabolic quadrilateral pyramid has a higher value of Io $33 \%$ of the parabolic collector system and $130 \%$ higher than the parabolic collector system with a flat mirror . While the output light intensity between the use of a secondary collector rectangular pyramid and cone difference is 5 lux.

d. Distribution of the output optical fiber

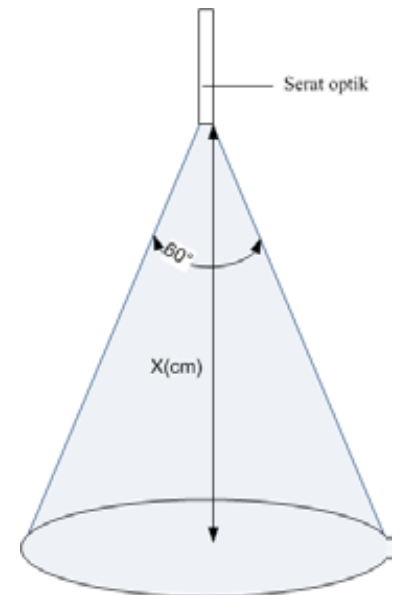

Figure 14. Intensity of light output from the optical fiber. 
This measurement is performed to find the relationship between the output light from the optical fiber with a certain distance (x). This measurement aims to determine the distribution of the intensity of the lighting in the room.

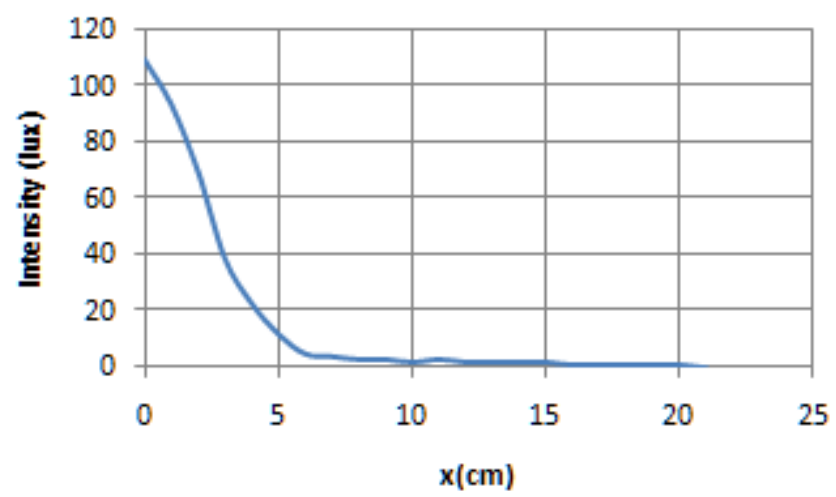

Figure 15. Graph showing the relationship intensity (lux) with $\mathrm{x}(\mathrm{cm})$.

Testing the value of the distribution of light in the room is done when Io $=110$ lux. It is seen that the intensity distribution of the optical fiber output ramp, according to the theory, that the intensity of light per unit area is inversely proportional to the square of the distance from the source.

\section{Summary}

- It has been designed transmission system consisting of solar lighting and fiber optic collector system for indoor lighting .

- Implementation of the design used in photonics Engineering Laboratory . The design of the transmission of solar lighting system consists of a main collector is the parabolic diameter of $80 \mathrm{~cm}$ with three variations of the secondary collector and fiber optic end glow with a length of $50 \mathrm{~m}$ and a diameter of $6 \mathrm{~mm}$.

- Characterization of the system include measurement reflectance value, the intensity of light output from the optical fiber, and the intensity distribution in the room .

- The results of the measurement of reflectance value of a paint color gray and silver on a parabolic surface , respectively 0.225 and 0.475 .

- The use of a parabolic collector system with a secondary collector cone produces the highest output compared to the other three collector system is 206 lux measurements with a standard deviation of 4.68 lux .

- Measurement of the distribution of the light output from the optical fiber corresponds to the results of the calculation, ie the light intensity per unit area is inversely proportional to the square of the distance from the source .

\section{Recommendation}

Further studies need to be done related to the requirements of the optical fiber to match the lighting conditions of the room as needed. 


\section{References}

[1] Taylor, Alma E.F. Illumination Fundamentals. United States: Lighting Research Center, 2000.

[2] Mahya Tauhidiya Nur, Sekartedjo. "Rancang Bangun Hybrid Solar Lighting: Solid State dan Fier Solar Lighting." Tugas Akhir Teknik Fisika, 2007

[3] Grisé, William, and Charles Patrick. "Passive Solar Lighting Using Fiber Optics." Journal of Indutrial Technology, 2003

[4] Kandilli, C., and K. Ulgen. "Review and Modelling the Systems of Transmission Concentrated." Elsevier, 200

[5] 03-6575-2001, SNI. "Tata cara perancangan sistem pencahayaan buatan pada gedung." 2001.

[6] Stine, William B. "Power from the Sun." www.powerfromthesun.net. 2003. www.powerfromthesun.net/Book/chapter08/chapter08.html (accessed Maret 12, 2012). 